\title{
Enhancing the Capabilities of Municipalities for Local Economic Development through Skills Training
}

\author{
Richard Douglas Kamara \\ PhD Student, Stellenbosch University (SU), South Africa \\ Samantha Leonard \\ Dr., Senior Lecturer, Nelson Mandela University (NMU), South Africa \\ Richard Haines \\ Professor, Nelson Mandela University (NMU), South Africa
}

\begin{abstract}
The purpose of this study is to investigate the extent to which the existing training interventions in municipalities can be able to build skills capacity for municipal staff to promote local economy, with special focus on two municipalities (Stellenbosch and Drakenstein), in the Cape Winelands District. Thus, it seeks to answer the following primary research question: To what extent can the existing training interventions help to build skill capacity for LED projects in two of the Cape Winelands' municipalities? To do this, the study seek to analyse LED training for municipal staff carried out in the two municipalities for the past five years with special focus on the transfer of the acquired skills into job in the work place.
\end{abstract}

The study is situated within the interpretivist paradigm, which focuses on meanings and attempts to understand the context and totality of each situation by employing the qualitative method of interviews which were conducted with staff and representatives of the municipalities and other key LED stakeholders in the two municipalities.

The methodological finding reveals the following mixed results: Although the two Municipalities seems to be making great strides in providing trainings, there are some contextual issues in their working environments which disenables transfer of skills to the job. These issues are: Limited supports, limited opportunities to career progression, lack of motivation, working in silos and limited opportunities to practice. However, this conclusion does not invalidate the promise of capacity building to transform the two municipalities into an efficient developmental agent, but highlights the importance of the critical factors which tends to shape the positive outcomes of capacity building initiatives.

Keywords: local economic development, capacity building, skills transfer, work environment, LED training.

JEL Classification: $\mathrm{O} 1$.

(C) The Authors, 2017. This article is published with open access at ARMG Publishing.

\section{Introduction}

A growing scepticism on the efficacy of traditional top-down development approaches has heralded a systemic proliferation in the search for alternative development strategies and to manipulate policies to remedy the imbalances of antecedent development approaches. The lack of effectiveness and the failures of these development policies and strategies prompted the advancement of new approaches that proposed decentralized, co-ordinated, integrated, context specific and bottom up strategies (OECD, 1998; World Bank, 1998). Put in simply, within this context of scepticism, controversy and disillusionment, an opportunity for more locally relevant and people-centred development rose to the fore. According to Sharma (2000) decentralized local governance contributes to development as it tends to promote participatory development strategies and the production of policies that are adapted to local needs. Therefore, the involvement of citizens in development planning and implementation often enables the formulation of realistic plans that are in line with local circumstances and conditions (Edoun and Jaheed, 2009).

In South Africa, the municipal system Act (Department of Planning and Local Government, 2000) has made it a legal requirement for municipalities to produce Integrated Development Plans (IDPs) in which due consideration is accorded to citizen involvement in the economic development agenda of their localities. According to Van de Heijden (2008), the municipalities lack capacity to monitor the quality of these plans, thus resulting in a cumulative trend towards the production of low quality LED plans marked by a project focus, unrealistic targets, an inability to identify the drivers of local development and poor implementation. Several 
LED training interventions have been made to improve the capability, effectiveness, responsiveness, and accountability, in sustainable forms, for local municipalities. Experience has shown that much still need to be done to bridge the capacity gap in the local municipalities (Abrahams, 2003). There are not many empirical studies conducted in the context of south African municipalities on capability enhancement through skills training for municipal staff towards the promotion of localised economy. Therefore, this study seeks to examine the extent to which the existing skills trainings for municipal staff in the two municipalities can improve their capabilities of fostering territorial development.

This study has undertaken a novel approach to contextualise skills training for territorial development within contemporary development thinking of human development and the capability approach. The paper, therefore, relies on the assumption that skills training needs to address not only the human capital needs of society, but also the development needs and aspirations of individuals as defined by the capability approach. This helps to improve our understanding of the social drivers that may inhibit or enable individuals in taking full advantage of training-led developmental interventions for furtherance of peoples' lives as well as to enhance their capabilities to accomplish development projects in their municipalities.

According to Marson, Parigi and Vaggi (2014: 1) "development is empowerment in the broad sense of the capability approach". A person or group is empowered when they have the capacity to make effective choices and to translate their choices into desired actions and outcomes. In addition, the theoretical contribution of this study builds on current literature which argue that neither opulence (income or commodity ownership) nor utility (happiness or desire fulfilment) are enough to conceptualize human well-being or deprivation (Bass, Nicholsen änd Subrahmanian, 2013; Clark, 2005; Robeyns, 2005). Within the capability approach, development itself should be a process that enables the expansion of real freedom - the opportunities of people. As rightly pointed out by the President of an opposition political party (Democratic Alliance) in South Africa during his inauguration speech, 'Freedom without opportunities is useless' (Maimane, 2015). Thus, it will also be observed in the study how enhanced capability through training can help empower local government staff to foster LED.

The study further provides an in-depth understanding of the capacity development program for LED in the two municipalities (Stellenbosch and Drakenstein) with regards to what works well in certain circumstances and what can be improved. This helps to broaden our knowledge on the development and use of effective capacity development strategies and knowledge products that could assist the policy makers and all the stakeholders involved in skills training interventions in the formulation of effective strategies that matches with the local needs.

The remaining parts of this paper is structures as follows: Contextualization of skills training through the lenses of capability approach; the methodology, where the various methods that were used to obtain and analyse the data were explained; background of CWDM; presentation of results emanating from the study; the discussions of the results, recommendations and conclusions.

\section{Contextualizing skills training through capability approach}

Human development is the expansion of people's freedom to live long, healthy and creative lives, advance other goals they have reason to value, and engage actively in shaping development equitably and sustainably on a shared planet. Interestingly, "people are both the beneficiaries and drivers of human development, as individuals and groups" (HDR, 2010: 22). The processes of human development often need a reorientation from a control perspective, to a stance of flexibility and ongoing learning, from a focus on short-term facilitated improvements to a focus on long-term action for changing behaviour, motivation and values, and organizational and institutional reforms.

From the human capital perspectives, efficiency is the yardstick for evaluating skills training in terms of its efficacy to enhance the performance of people in the work place. Thus, it makes people more productive and therefore can receive higher wages. However, with Sen's capability, learning is being evaluated beyond economic reasons to reflect other human behaviors. Stemming from the context of this paper, the analytical question is: To what extent can skill training contribute towards building a more just society, with regards to human dignity and wellbeing?

According to Sen (2000) learning plays an instrumental role in enabling people's capacity to participate and make good decisions at all levels. Therefore, the researcher is quick to add that an effective training, should be capable of transforming and empowering municipal staff on how to design and implement LED policies and programs which are well responsive to local developmental issues within their municipalities. It can 
further be argued that learning enhances freedom and opportunity for individuals to do what they consider valuable for the fulfilment of their wellbeing. Therefore, this helps to buttress the imperativeness of skills training in South Africa as a tool to redress the injustice of marginalization and segregation, by facilitating the ability of previously disadvantaged group to participate in social, political and economic development.

In contrast to the traditional perspective of development which sees economic growth as the objective of development, Duraiappah, Roddy and Parry (2005) argue that the capabilities approach views development as a means of improving human well-being and agency. From such a viewpoint, capabilities thus open a way to think together about the economic development of the organization and the development of people in the workplace. This takes into consideration what a person can do in terms of his or her competences as well as the real possibilities this person should develop and implement his or her competences (Zimmermann 2004). Therefore, the opportunities available to employees in the workplace and the means to act on them are of paramount importance to the success of any skills development initiatives.

As argued by Zimmermann (2004) capabilities at work encompass many dimensions ranging from capability for work to capability for voice, capability for learning, as well as capability for work-life balance. While being competent involves the exercise of responsibility at work, capabilities include, in addition, the means to exercise this responsibility. The study of Csikszentmihalyi (2003) found that people tend to be satisfied in their workplace when their work provides equilibrium between their abilities and the challenges they face, and when a balance between opportunities to distinguish themselves through individual achievement and occasions to contribute to overarching group goals is provided. It therefore becomes imperative for managers to create the enabling working environment which facilitates as many moments of 'flow' as possible. To this end Poolman (2012: 31) argues that "the extent to which people's real freedom can be expanded is dependent on how well those in power value it and actively incorporate it".

In addition, Lambert and Vero (2013: 394) argue that at "the core of the capabilities approach stands the premise that exercising any responsibility requires a scope of choice between various possible options and a power to convert the chosen option into an actual achievement". Consequently, if the employee is called to function well in his/her duty, from an operational point of view he/she should be given the means to enable them to take this responsibility. Therefore, the need to examine the extent to which a person can transform a means (resources) into a function (capabilities) become imperative. For this study, in trying to examine the extent to which the existing trainings in LED for municipal staff can be able to build capabilities for the municipalities, the study also examines and conceptualises the abilities of the municipal staff to convert these capabilities provided by the trainings into functions, as it seeks to thoroughly analyse the contextual issues in the workingenvironment which tends to enable or disenable skills transfer into workplace

According to Otto and Ziegler (2006) agents differ in their ability to convert capabilities into functions. Crocker (2008: 171) argues that capability does not refer exclusively to a person's abilities or other internal powers but to an opportunity made feasible, and constrained by, both internal (personal) and external (social and environmental) conversion factors. Some differences are more closely related to individual characteristics, others to social differences and yet others to the surrounding work environment.

From the perspectives of the capabilities approach, desire to learn encompasses all the opportunities, rules and procedures involved in gaining access to training, as well as those involved in converting the training into valuable achievements. Vero and Lambert argue that a personal willingness to be trained does not derive exclusively from individual motivation. It is intimately interwoven with the substance of managerial intervention at the workplace, the kinds of management policies pursued within the organization in terms of allocating resources, the training opportunities provided and the deliberation spaces they set up. Organizations, therefore, act as a conversion operator of resources into capabilities (Lambert and Vero, 2010; Zimmermann, 2008). Therefore, the goal of fostering and sustaining individual capabilities can only be achieved if viable collective frameworks and arrangements exist. Hence the importance of collective social supports (rights, institutions, rules, networks and so forth) so that individuals have at their disposal the opportunities required to convert resources into desirable or valued outcomes, as defined by themselves (Zimmermann, 2006).

Lastly the extent to which the learning resulting from training is being transferred to the job, thus bringing about meaningful individual behavioural changes which result in improved work performance is of paramount concern in organizational training efforts (Goldstein and Ford, 2002). According to Wolf and deShalit (2007) the underlying idea is that a policy cannot limit itself to providing people with some capacity, but capacity should be provided in such a way that people can rely on it in the future. 


\section{Research methodology}

This study was undertaken in the Stellenbosch and Drakenstein local municipalities, located in Cape Winelands District municipality (CWDM) in Western Cape, South Africa. A purposeful sampling strategy of a non-random selection of participants was utilised for selecting the participants that constituted the target group of this study. The choice of the two municipalities is informed by the municipalities orientation towards LED strategy, being one of the few local municipalities in the province with established LED units and framework. The study is situated within the interpretivist paradigm, which focuses on meanings and attempts to understand the context and totality of each situation by employing the qualitative method of interviews which were conducted with staff and representatives of the municipalities and other key LED stakeholders in the two municipalities. Thus, interviews were conducted with 22 different stakeholders drawn from the Department of Cooperative Governance and Traditional Affairs (COGTA), South African Local Government Association (SALGA), Local Government Sector for Education and Training Authority (LGSETA), Department of Economic Development and Tourism (DEDAT) (Western Cape), the Cape Winelands District Municipality, the Stellenbosch Municipality and the Drakenstein Municipality. The qualitative data were analysed with the aid of a computerised qualitative data analysis software called Atlas.ti. The software was utilised to generate the emerging themes through a thematic coding process.

\section{Background of Cape Winelands District Municipality (CWDM)}

The Cape Winelands District Municipality is one of six district municipalities located within the Western Cape Province in South Africa. The district consists of five local municipalities, namely: Witzenberg Local Municipality (WLM); Drakenstein Local Municipality (DLM); Stellenbosch Local Municipality (SLM); Breede Valley Local Municipality (BVLM); and Langeberg Local Municipality LLM). The CWDM occupies an area of 22,318 km2 as indicated in Figure 1.

The average annual income levels of households residing in the district shows that $51.6 \%$ of the population fall within the low-income bracket (USD 0 - USD 3,000), which is also identified as the poverty level. These household generally have difficulty meeting their basic needs. $44.7 \%$ of households fall within the middle-income group (USD 3,001 - USD 24,000) and only 3.7\% of households fall within the high-income bracket (USD 24,001 and more). The average annual household income within the area will not increase unless the skills of the household members improve through better education attainment opportunities and job creation in higher skilled economic sectors (CWDM, 2011).

In terms of the performance and structure of the economy, statistics have shown that $48.4 \%$ of the population is employed, $40 \%$ are not economically active and $11.6 \%$ of the population is currently unemployed. The $48.4 \%$ employed population can be divided into the individuals employed in the informal sector (5.7\%) as well as the individuals employed in the formal sector (42.7\%). Given the business opportunities stemming from each economic sector within the District Municipality, data shows that the community and personal services sector contribute to $27.3 \%$ of the employment opportunities within the CWDM. The second largest contributing sector is the agricultural sector $(19.2 \%)$, followed by the trade sector $(19 \%)$, manufacturing $(14.6 \%)$ and the finance and business services sector (11.6\%). Half of the formally employed population is employed in semi- and unskilled occupations. $39.4 \%$ of the formally employed population is employed in skilled occupations and only $10.7 \%$ are employed in highly skilled occupations.

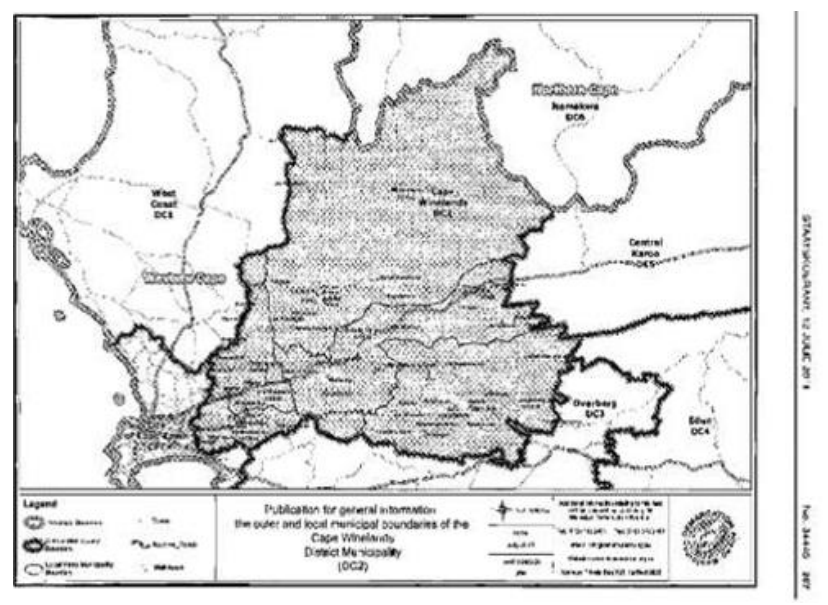

Figure 1. Cartography of CWDM (Municipal Demarcation Board, 2011) 


\section{Results}

The themes emanating from the study are presented below in Table 2. The themes identified in this study were consistent with those that were anticipated beforehand, whilst others emerged and added to the researcher's overall understanding of capacity building for LED in the municipalities. These themes profoundly reflect the views, comments, experiences and aspirations of major LED stakeholders in the two municipalities in Cape Winelands districts which constitutes the centre piece of this study. Moreover, it concisely mirrored the dimensions as to what extent the existing training interventions can be able to build skill capacity for LED projects in the Cape Winelands municipalities as perceived by the key stakeholders. Thus, six main themes emerged from the analysis of the data.

The work place environment where the municipal staff need to apply their newly acquired knowledge, skills and attitude to job were examined. This was done to establish the level of training transfer into the workplace. The emerged data from the interviews points out some contextual factors in the work environment which tends to influence the transfer of acquired skills in training into the workplace as presented in figure 2 and discussed below in details.

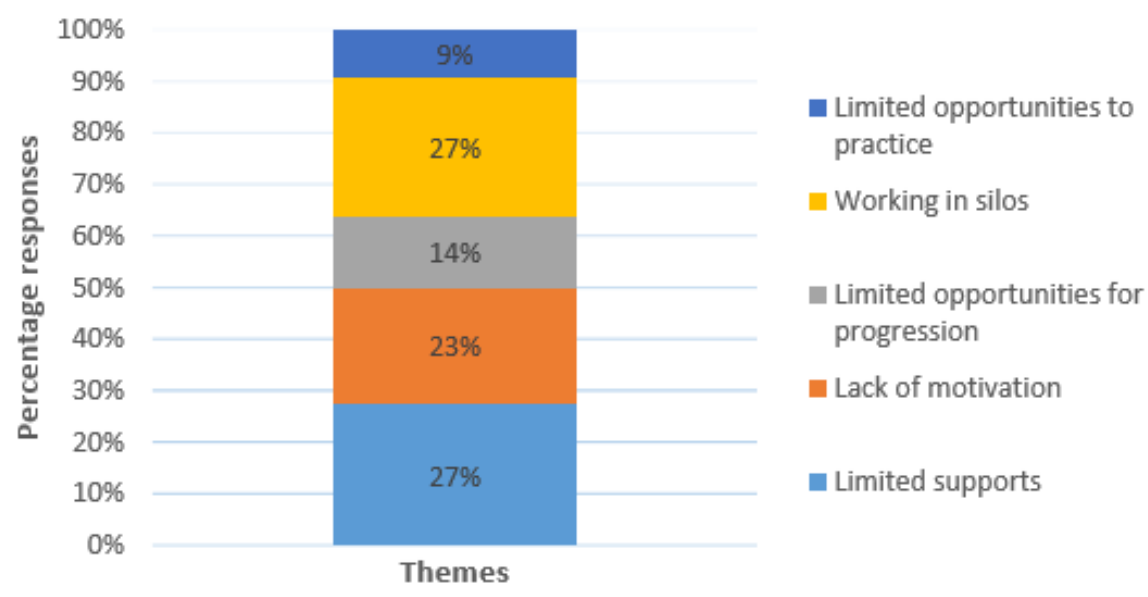

Figure 2. Contextual factors - transfer of training

\section{Limited support}

The interview data revealed that $27 \%$ of the responses received acknowledged that there is no follow-up supports on trainings in the two municipalities as could be deduced from the following statements made by some of the respondents:

"There has never been any follow up on any training. For the ones that I have participated it has all been once off".

"It is not always budgeted for and as a service provider, we don't put emphasis on follow-up and support as the client normally does not pay for that, so it will be a wasteful exercise, it is an unnecessary expense for the service providers".

\section{Lack of motivation}

The interview data revealed that $23 \%$ of the respondents embraced the importance of motivating their workers. The respondents acknowledged that there is no incentive scheme in place in the municipality to motivate trainees to apply what they learnt in training at work. To this, a Councillor in one of the municipalities acknowledged that:

"There are ways that people will receive some recognition for work they have done unfortunately that also happen but you are asking very important questions and the whole issue about motivation is crucial because if you don't have motivation and what will you do in your work/offices without no motivation and the only motivation is to be promoted to get a better salary and if you don't get you will feel frustrated."

\section{Limited opportunities to progression}

The interview data revealed that $14 \%$ of the respondents acknowledge that there is no formal performance management system in their municipalities. To this one of the respondents mentioned that: 
"I must mention that it's not actually formally, formally especially in local government, especially in our Municipality I don't know about the others but I know mostly they don't have it effectively implemented."

Another respondent responded thus: "Our performance management at this point in time is only catering for Senior Management. We have different phases where it is going to be rolled down to employees."

\section{Working in Silos}

The interview data shows that LED is not fully integrated with other functional departments in the municipality. In other words, in most municipalities, LED practices are confined to the LED units in the municipalities. $27 \%$ of the participants believe that the LED department is not completely fused with other departments in the municipalities as indicated by comments such as:

"Our department are still working in silos and as I'm saying LED supposed to be in all the departments, it supposed to be involved in all department, at the end of the day there are chances of development in all the department, here they are still working in silos."

In addition, another respondent asserted that even within the department of LED, there is still a rift.

"That is precisely what is happening in LED that they the managers don't want to speak to the deputy manager, the deputy managers don't want to speak to the officers and the officers is battling with the clerk, and nobody talks to each other."

\section{Opportunities to practice}

The interview data shows that on completion of the training most of the trainers were not given the opportunity in the workplace to put what they had learnt in the training into practice. In other words, trainees are being hindered from transferring acquired skill and knowledge into the job. Thus $9 \%$ of the respondents bears witness to the foregoing claim. Below is an excerpt from the interview as mentioned by one of the respondents.

"It depends on the demands of the department sometimes you can go to training then the department will need you to do something totally different else that is what is a fear". However, another participant acknowledged that "Some does while others don't. It all depends on the attitude of the trainee."

\section{Discussions}

The principal objective of LED should be to build the economic capability of local areas for sustainable economic development. According to Watson (2006), an essential component of community-led rural development is the ability of local people to solve their own problems. As Maserumule (2008: 441) had correctly argued that "for the municipalities to succeed in establishing themselves as developmental local government structures, they will need strategic, organizational, and technical capacities". The continuing challenges we face therefore, is one of ensuring that all municipalities develop the requisite capacity to be able to work towards the achievement of its developmental mandate. However, current experience with the implementation of LED programs in South Africa indicates capacity gaps in different areas across all districts and municipalities to implement the program (Rogerson, 2009). This problem provided an impetus for this study to be undertaken in the two municipalities.

This part of the study discusses the main arguments and research findings of the study within the framework of the identified research problem and stated research objectives of the study. The study has attempted to determine the extent to which LED capacity building training in Stellenbosch and Drakenstein municipalities can impact on LED practices in the two municipalities. This final segment of this study therefore aims to directly answer the research question of this study.

To provide plausible answer to the research question of the study, analysis was carried out on the generated data with special focus on how well the municipal staff are being able to transfer acquired skill training on LED into jobs in their workplace.

The answers to this research question unfortunately remains mixed. The study has examined how authority in the two municipalities (Stellenbosch and Drakenstein) aims to provides the opportunities for municipal employees to improve their technical and behavioural capabilities needed in the municipalities to render all the services required to foster LED. Although trainings may be efficiently delivered, the trained staff in the two municipalities found it difficult to transfer into jobs their newly acquired skills due to lack of enabling 
workplace environment. The trained staff are faced with limited supports in terms of post-training follow-up supports such as coaching and mentorship, the staff becomes demotivated as there are limited opportunities for career progression, staff working in silos and lack of opportunities to practice learned skills at workplace.

It should however be noted that the paramount concern of organizational training efforts is the extent to which the learning outcomes from the training are being utilised or transfer into the job to enhance performance at work (Goldstein and Ford, 2002). The findings of this research indicate that the staff were not being mentored or coached after the training. Most often than not, the trainings were designed to be once- off without any follow-up. In other words, each training tends to be of an isolated event with no continuity. This finding seems to buttress the argument of Matovu (2013: 6) that "most of the training programs are supplydriven and in most institutions, there are no resources available to enable training institutions to undertake post-training evaluation on the impact of their training programs on the client organization". In addition, findings from extant studies show that the ability of supervisors to provide adequate support for example, supervisory encouragement to attend training and apply the knowledge, skills and attitude acquired onto the job and to use a comfortable communication style such as the supervisor providing clear feedback, is a major determinant of the transfer of training in the organization (Lim, 2008).

In addition, it was found out in the research that though staff were being trained to enhance their performances at work, there was lack of corresponding motivations with regards to career progression. Therefore, the staff becomes demotivated and often opt for another job elsewhere with better package. This finding appears consistent with the argument that the practice of LED in many municipalities in South Africa becomes either a 'dumping ground' for ineffective officials or only a stepping stone for competent local government personnel because of LED's constrained career prospects (Rogerson, 2010).

Paradoxically, it has been found in the study that the skill training that could have been able to foster the culture of collaboration, shared value and network between the functional departments in the two municipalities failed to create the desired social capital to enhance LED practices in the municipalities. Thus, LED is not fully integrated with other functional departments in the municipality which makes LED practices in the two municipalities confined to the LED units in the municipalities. This finding seems to concur with the argument raised by SALGA (2009) with regards to the issues of LED not often given the political weight and attention it deserves as one of the key priorities of government, hence, the limited alignment, integration and cooperation between district, local and/ provincial initiatives.

Finally, the study found that on completion of the training most of the staff were not given the opportunity in the workplace to put what they have learned in the training into practice. This seems to constitute another demotivating issue which hinders training efficacy. Some research studies have found that positive transfer is limited when trainees are not provided with opportunities to use new learning in their work setting (Gaudine and Saks, 2004; Lim and Morris, 2006; Raliphada, Coetzee and Ukpere, 2014). Similarly, the study of Nikandrou, Brinia, and Bereri (2009) found that people who believe and know in advance that they will not have any opportunity to apply their new skills did not transfer their training to their work. Therefore, failure within each of these parameters undeniably indicates the potential inability to reach the desired outcomes embodied in a well-meaning capacity building training designed to improve development management and responsiveness to socio-economic issues within the municipalities.

However, this conclusion does not invalidate the promise of capacity building to transform the two municipalities into an efficient developmental agent, but highlights the importance of supportive work environment (adequacy of supports, motivations, shared values and collaborations) are all critical factors shaping positive outcomes. Nonetheless, the Researcher is still optimistic that capacitating the staff in the two municipalities through training remains the most effective means that could be used to improve the capabilities of the staff in the two municipalities to be able to have influence over their situation and thereby boost their LED practices in the municipalities.

\section{Recommendations}

To implement the capacity building strategies effectively and efficiently, there is a need to promote training transfer into jobs in the two local municipalities (Stellenbosch and Drakenstein) so that wastage of resources can be avoided and the intended objectives and impact of the capacity building strategies are achieved. The various recommendations arising from the findings of this study are highlighted below. 
To address the low staff morale resulting from inadequate implementation of performance management systems, there should be a strategy for work practices and an improved and well managed Performance Management System (PMS) for the local governance in both municipalities.

A strategy should be in place to monitor and evaluate the processes, procedures and outcomes of municipal staff capacity building projects. The national through the provincial and district level need to co-ordinate capacity building interventions in the local municipalities. The two local municipalities (Stellenbosch and Drakenstein) needs to develop their own capacity building strategy that embraces the culture of monitoring and evaluation of processes, procedures and outcomes of capacity projects in their municipalities. On this note, it can be further recommended that a monitoring and evaluation committee should be constituted and be operationalised in each municipality. The committee should be principally charged with the responsibilities to oversee, monitor and evaluate the implementation and outcomes of municipal staff capacity building projects.

Trainees should be encouraged to freely and positively share with their co- workers what they learnt in LED training as the recognition of their good practice by their co-workers enhances the learning culture of the municipality. On this note, it's recommended for the two municipalities to set up something like "Staff forum" where municipal workers could freely share work related ideas with their co-staff.

$>$ The operationalisation of LED should not be confined solely to responsibilities of LED units alone but should be in all other functional areas in the municipality. There is the great need to integrate LED practices with other functional department in the two municipalities in question. A paradigmatic shift awareness campaign needs to be carried out in both municipalities to deconstruct their mentalities of confining LED practices to LED unit. The two municipalities needs to put in place a change management strategy, including communication plan.

$>$ Developing all supervisors to become performance coaches - supervisors could become active transfer agents in the process of ensuring learning transfer success. The ability to assist Trainees when they returned to the workplace upon the completion of a training intervention becomes an enabler of successful transfer of training.

$>$ To enhance effective transfer of training in job applications, supervisors should be taught how to be supportive as well as be capable of monitoring whether the newly acquired skills are being applied correctly in the work place

$>$ In addition, the intrinsic motivation possessed by the employees to transfer their learning should not be dampened by any barriers. Barriers to learning transfer emerges when the supervisors prevent the employees from using their newly acquired knowledge and skill when they return to the workplace. On return from their training, they should be given the time and opportunities to practice in their job what they have learnt in training. Their Supervisors should continue to motivate employees to transfer their learning.

$>$ Trainees should endeavour to be intrinsically motivated to transfer their learning even if they are not fully supported by their supervisors. They must remain motivated and focussed to turn their knowledge and skill into increased work performance.

$>$ The two municipalities should endeavour to build in post-training follow-up into their training design and delivery. Post-training follow-up helps the trainer and the municipalities to monitor and evaluate the effectiveness of training design and delivery through the job application of the newly acquired skills and knowledge by the trainees. This will help both the trainers and the municipalities among other things to discern between what works well and what does not work well and under what circumstances. This would help to improve on the design and delivery of future training.

\section{Conclusion}

The primary aim of the study has been to assess the extent to which the existing training interventions can help to build the skill capacity for LED projects in two of the Cape Winelands Local Municipalities. Undoutedbly, the Researcher is obliged to argue that the empirical evidence shows the various contextual issues in the working environments which disenables the municipal staff to transfer acquired skills in the training into the workplace environment. Issues such such as limited supports, lack of motivation, limited opportunities to progression, lack of opportunities to practice and working in silos. Amidst all these shortcomings, it's 
very difficult to witness any plausible impacts of the LED capacity building trainings on the practices of LED in the two municipalities.

Nonetheless, the findings of this study do not per se, erodes the credibility of LED training to transform LED practices in the two municipalities in question, but highlights the imperativeness of embracing all critical factors that shapes the positive outcomes of any LED capacity building initiatives for municipal staff.

It is the opinion of the researcher that the aforementioned recommendations are practical and if implemented would help to improve the performance outcomes of municipal staff as result of changing capacity and ultimately increased project sucess and sustanaibility. Moreover, the researcher hopes that the recommendations for this study will enable LED stakeholders in the two municipalities to understand and proactively manage the contextual variables influencing learning transfer in their institutions and thus mitigate these barriers to ensure successful and sustainable capacity building outcomes within local municipality.

\section{References}

1. Abrahams, D. (2003). Local economic development in South Africa: a useful tool for sustainable development. Urban Forum, 14, 185-200.

2. Bass, J., M., Nicholsen, B., and Subrahmanian, E. (2013). A Framework Using Institutional Analysis and the Capability Approach. ICT4D, 9(1), 19-35.

3. Crocker, D. (2008). Ethics of Global Development: Agency, Capability, and Deliberative Democracy. Cambridge: Cambridge University Press.

4. Csikszentmihalyi, M. (2003). Good business: Leadership, Flow and the Marking of Meaning. London: Hodder and Stoughton.

5. Department of Provincial and local government affairs (DPLG) (2000). Local Economic Development: Guidelines for Institutional Arrangements. Local Economic Development Series, Volume 1. Pretoria: DPLG.

6. Duraiappah K. A., Roddy P., \& Parry J. (2005). Have Participatory Approaches Increased Capacities? International Institute for Suitable Development, Canada.

7. Edoun, E. I. and Jaheed, M., (2009). The merits of decentralisation and local economic government in South Africa. Global Action for Africa's Development (GLAFAD). Pretoria, South Africa.

8. Gaudrine, A. P., and Saks, A. M. (2004). A longitudinal Quasi-experiment on the effect of post training transfer intervention. Human Resources Development Quarterly, 15(1), 57-76. http://onlinelibrary.wiley.com/doi/10.1002/hrdq.1087/pdf. [Accessed on 17 August 2013].

9. Goldstein I. L., and Ford K. (2002) Training in Organizations: Needs assessment, Development and Evaluation $\left(4^{\text {th }}\right.$ Edn.). Belmont: Wadsworth.

10. HDR (2010). Human Development Report 2010, United Nations Development Program (UNDP). Palgrave Macmillan, New York.

11. Lambert, M. and Vero, J. (2013). The capability to aspire for continuing training in France. International Journal of Manpower, 34(4), 305-325.

12. Lim, D., Johnson, S. (2008). Trainee perceptions of factors that influence learning transfer. International Journal of Training and Development, 6(1). Blackwell Publishers Ltd., Oxford, UK.

13. Lim, D. H. and Morris, M. L. (2006). Influence of trainee characteristics, instructional satisfaction, and organizational climate on perceived learning and training transfer. Human Resource Development Quarterly, 17(1), 85-115.

14. Maimane, M. (2015). Party Leader Inauguration speech. Democratic Alliance National Convention. Port Elizabeth. South Africa.

15. Marson, M., Parigi, G. B., and Vaggi, G. (2014). The empowerment Approach to evaluation the case "Project Malawi". 14th EADI General Conference 23- 26 June 2014, Bonn. Germany.

16. Maserumule, M. H. (2008). Framework for strengthening the capacity of municipalities in South Africa: A developmental local government perspective. Journal of Public Administration, 43(3.2).

17. Matovu, G. (2003). A draft working paper on Regional Dimensions of Capacity Building for Municipal Governments: Experiences and Lessons learned from Eastern and Southern Africa. Municipal Development Partnership - Eastern and Southern African.

18. Nikandrou, I., Brinia, V., and Bereri, E (2009). Trainee perceptions of training transfer: an empirical analysis. Journal of European Industrial Training, 33(3), 255-270. Available at http://0- 
www.emeraldinsight.com.wam.seals.ac.za/journals.htm?issn=0309-

0590\& volume $=33 \&$ issue $=3 \&$ articleid $=1784684 \&$ show $=$ pdf. [Accessed on 17 August 2013] .

19. OECD (1990). Partnerships for Rural Development. Paris: OECD.

20. Otto, H. and Ziegler, H. (2005). The Capabilities Approach. Education Social Work and Society, 4(2), 269-287.

21. Poolman, C. (2012). Humanity in the Capabilities Approach to Development. POLIS Journal, 7, 366408, University of Leeds, UK.

22. Raliphada, N., Coetzee, J., and Ukpere, W. (2014). Organizational Factors Affecting Learning Transfer In The South African Public Service. Mediterranean Journal of Social Sciences, 5(1), 743-754.

23. Robeyns, I. (2005). Selecting capabilities for quality of life measurement. Social Indicators Research, 74(1), 191-215. Available at http://dx.doi.org/10.1080/146498805200034266. [Accessed on 24 April 2015].

24. Rogerson, C. M.(2009). Strategic Review of local economic development in South Africa. Final report submitted to Minister S Shiceka of Department of Development Planning and Local Government (DPLG). Commissioned by DPLG and GTZ. May 2009.

25. Rogerson, C. M. (2010) Local economic development in South Africa: Key strategic challenges. Development Southern Africa, 27(4), 481-495. [Accessed on 27 April 2015].

26. SALGA, (2009). Role of 3 spheres of Government in LED and the role of SALGA in economic development. Available at http://www.pmg.org.za/report/20111025-salga-its- role-local-economicdevelopment-and-also-brief-committee-mu. [Accessed 25 June 2013].

27. Sen, A. (2003, October 28). The importance of basic education [full text of speech to the Edinburgh Commonwealth education conference]. The Guardian. Retrieved from http://people.cis.ksu.edu/ ab/Miscellany/basiced.html.

28. Sharma, K. (2000). Popular Participation in Botswana. In United Nations (UN), Decentralisation and Citizen Participation in Africa, Regional Development.

29. Subramanian, D., Verd, J. M., Vero, J., and Zimmermann, B. (2013). Bringing Sen's capability approach to work and human resource practices. International Journal of Manpower, 34(4), 292-304. http://dx.doi.org/10.1108/IJM-05-2013-0092. [Accessed on 23 April, 2015].

30. Van der Heijden, T. (2008). Key issues in Local Economic Development in South Africa and a potential role for SALGA. Unpublished Position Paper prepared for the South African Local Government Association.

31. Watson, D. (2006). Monitoring and evaluation of capacity and capacity development. European Centre for Development Policy Management (ECDPM).

32. Wolff, J. and De-Shalit, A (2007). Disadvantage, Oxford: Oxford University Press.

33. World Bank (1998). Public Expenditure Management Handbook. Washington D.C: The World Bank.

34. Zimmerman, R. A. (2008). Social capital and community membership. Journal of Vocational Rehabilitation, 29, 173-178.

35. Zimmermann, B. (2004). Competences-oriented logics and the politics of employability. In Salais, R., Villeneuve, R. (eds., 2004). Europe and the Politics of Capabilities, 38-53. Cambridge: Cambridge University Press. 